\title{
A spiking model of superior colliculus for bottom- up saliency
}

\author{
Micah Richert ${ }^{1}$, Jayram Moorkanikara Nageswaran ${ }^{1 *}$, Sach Sokol${ }^{2}$, Botond Szatmary ${ }^{1}$, Csaba Petre ${ }^{1}$, \\ Filip Piekniewski ${ }^{1}$, Eugene Izhikevich ${ }^{1}$ \\ From Twenty Second Annual Computational Neuroscience Meeting: CNS*2013 \\ Paris, France. 13-18 July 2013
}

Active exploration of visual space is controlled by a saccadic system using a combination of bottom-up and topdown signals. Rate based models [1] and simple V1 models (e.g. [2]), have been proposed to explain bottom-up or "pop-out" attentional mechanisms. We present a biologically detailed spiking model of superior colliculus to generate saccadic eye movements using a competitive mechanism based on spike arrival times. Various pop-out tasks based on color, orientation features and motion is used to analyze the reaction time of the model.

The superior colliculus is modeled as a two layer network with feature-specific superficial layers driving a common deep layer. The superficial layers of the superior colliculus are topologically organized and is driven by retinal parasols cells, V1 layer $2 / 3$ orientation-selective cells, V1 layer $2 / 3$ color-selective cells, and MT cells. These enable luminance, orientation, color and motion based popout respectively. In this model, the earliest spikes are considered the most salient. A saccade is triggered when there is a consistent winner in the superficial layers at the same spatial region over an extended period of time, $40 \mathrm{~ms}$ to $100 \mathrm{~ms}$. The superficial layers implement a temporal winner-take-all mechanism; specifically, there exists a separate inhibitory subnetwork that allows each superficial layer to choose a winner. The deep layer integrates these winners over time and selects a single spatial region. It implements a bump attractor network mediated by short-range excitation (AMPA and NMDA) and long range inhibition, which generates a bump of activity before and during a saccade. An interesting property of bump attractor network based circuit is that a single cell response is independent of size of the stimulus. Similar spiking response was also observed in most of the visually selective superior colliculus cells in monkeys [3]. Additionally, this model captures known behavioral and neurophysiological properties of the superior colliculus such as saccadic suppression, activity buildup before saccade generation, and GABAb mediated inhibition from the deep layer to superficial layers resulting in selective inhibition in recently attended region. All the connections in the SC model are pre-wired to satisfy the response characteristics of superficial and deep layers.

The reaction time of the model was tested on simple and conjunctive pop-out tasks. We observe only a mild shift in reaction time based on the number of distractors. Higher reaction time was observed as the complexity of the search task was increased. Also, reaction time increases based on the level of visual hierarchy that is connected to the superior colliculus layers.

\section{Conclusion}

A spiking model of superior colliculus is presented that demonstrate many interesting dynamics observed in superficial and intermediate layers of the superior colliculus [3]. A simple reaction time analysis of the model showed latency ranges that match the hierarchy of the incoming visual layers, with simple features eliciting much faster response than more complex features.

\section{Author details \\ ${ }^{1}$ Brain Corporation, San Diego, CA 92121, USA. ${ }^{2}$ Mind Brain Institute, John Hopkins University, Baltimore, MD 21218, USA.}

Published: 8 July 2013

\section{References}

1. Itti, Laurent, Christof Koch: Computational modeling of visual attention. Nature reviews neuroscienc 2001, 194-203.

* Correspondence: nageswaran@braincorporation.com

${ }^{1}$ Brain Corporation, San Diego, CA 92121, USA

Full list of author information is available at the end of the article

C 2013 Richert et al; licensee BioMed Central Ltd. This is an Open Access article distributed under the terms of the Creative Commons 
2. Li , Zhaoping: A saliency map in primary visual cortex. Trends in cognitive sciences 2002.

3. Goldberg, Michael E, Robert HWurtz: Activity of superior colliculus in behaving monkey. I. Visual receptive fields of single neurons. J Neurophysiol 1972, 192:542-559.

doi:10.1186/1471-2202-14-S1-P185

Cite this article as: Richert et al:: A spiking model of superior colliculus for bottom-up saliency. BMC Neuroscience 2013 14(Suppl 1):P185.

Submit your next manuscript to BioMed Central and take full advantage of:

- Convenient online submission

- Thorough peer review

- No space constraints or color figure charges

- Immediate publication on acceptance

- Inclusion in PubMed, CAS, Scopus and Google Scholar

- Research which is freely available for redistribution

Submit your manuscript at www.biomedcentral.com/submit
() Biomed Central 